\title{
THE RELATIONSHIP BETWEEN PHYSICAL FITNESS PARAMETERS AND BODY MASS INDEX IN YOUNG HEALTHY SEDENTARY ADULTS
}

\author{
Ibrahim Farooque ${ }^{1}$, Gauhar Hussain *2. \\ ${ }^{1}$ Associate Professor, Department of Physiology, F.H. Medical College, NH-2, Tundla, Firozabad, \\ U.P., India. \\ ${ }^{* 2}$ Associate Professor, Department of Physiology, F.H. Medical College, NH-2, Tundla, Firozabad, \\ U.P., India.
}

\section{ABSTRACT}

Background: Physical fitness can be assessed by suitable cardiopulmonary fitness parameters like Physical Fitness Index (PFI) and maximal oxygen consumption $\mathrm{VO}_{2}$ max. Because of lack of regular physical exercise, medical students have sedentary lifestyle and tend to be overweight. This study was done to assess the relationship between the physical activity and cardiorespiratory condition.

Materials and Methods: 80 sedentary male students were taken for the study. BMI was calculated from the anthropometric data. Physical fitness Index (PFI) and $\mathrm{VO}_{2}$ max of students were calculated after exercise. Statistical Analysis was performed using SPSS version 20.

Results: Negative correlation was found between physical fitness parameters and BMI.

Conclusion: The physical fitness of subjects varies inversely with the BMI. Increased BMI pose increased risk of additional health problems.

KEY WORDS: Physical fitness, BMI, PFI, $\mathrm{VO}_{2}$ max.

Address for correspondence: Dr. Gauhar Hussain, Associate Professor, Department of Physiology, F.H. Medical College, NH-2, Tundla, Firozabad, U.P., India. Tel: +919837512840

E-Mail:g_h303@yahoo.co.in

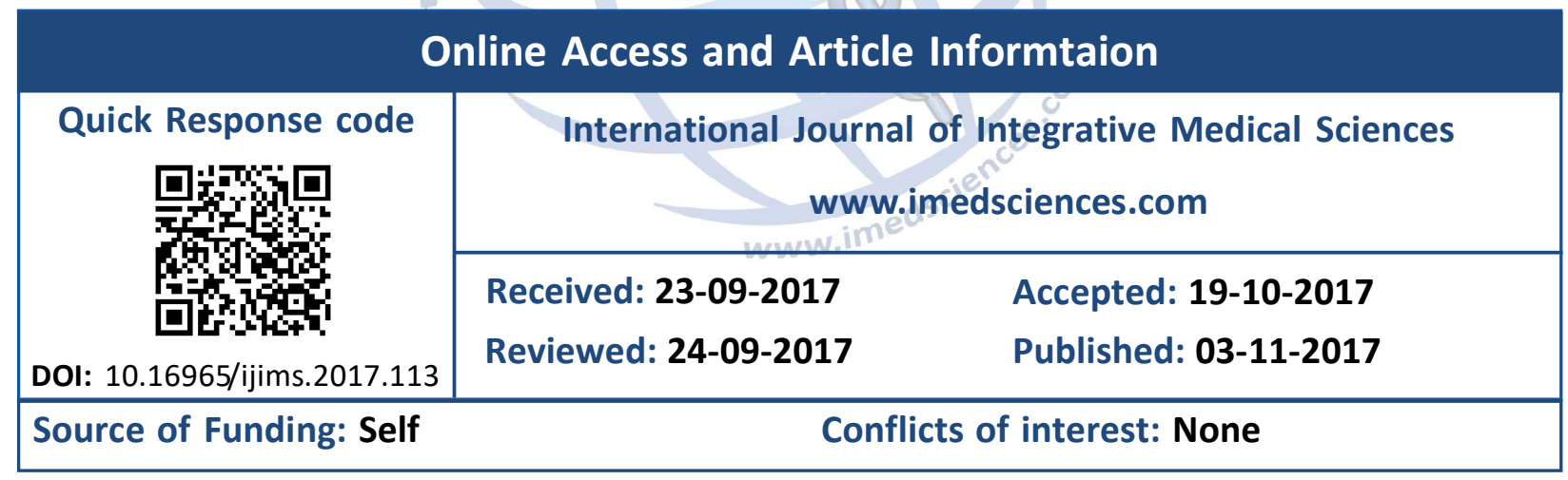

\section{BACKGROUND}

Physical fitness is defined as the ability to carry out daily tasks with vigor and alertness without undue fatigue and with ample energy to enjoy leisure time pursuits, to meet unusual situations and unforeseen emergencies [1]. For a common man, the physical fitness is ability to withstand stress and pressure under different circumstances where an unfit person would be ineffective or would quit.

Physical fitness can be assessed by suitable cardiopulmonary fitness parameters like Physical Fitness Index (PFI in \%) and maximal oxygen consumption that is $\mathrm{VO}_{2} \max (\mathrm{ml} / \mathrm{kg} / \mathrm{min}) . \mathrm{VO}_{2}$ max reflects the amount of oxygen utilized by working muscles and is a globally accepted measure of cardiorespiratory fitness [2]. $\mathrm{VO}_{2}$ max is the maximum amount of oxygen a person can intake and the value does not change despite an increase in workload over time period. $\mathrm{VO}_{2}$ max provides indices of the functional reserve of the organ systems involved and limitations that can be encountered at peak exercise $[3,4]$.

Direct measurement of cardiorespiratory fitness in terms of $\mathrm{VO}_{2}$ max is restricted within the well equipped laboratory because of its exhausting 
and difficult experimental protocol [5]. Among various indirect protocols $[5,6]$ the Queen's College step test or QCT is the simplest one and has already been established as the best indirect method to evaluate cardiorespiratory fitness in young Indian individuals [7].

The current education system in our country has helped to improve the educational standards, but the non active sedentary stressful life has made the youth physically unfit. We are neglecting the natural physical activities because of the sedentary lifestyle. Students of M.B.B.S course have a schedule consisting of lectures, practical and examinations, due to which making time available for exercise is difficult. Because of lack of regular physical exercise, good proportion of students tends to be overweight. Overweight and obesity are associated with hemodynamic changes at rest. It is worthwhile to study whether sedentary and mentally strenuous lifestyle is affecting their cardiovascular fitness or not. In general, obese adults have lower fitness levels compared to the normal population [8].

Most popular index to compare body composition of people and to categorize them as obese and non obese is the Body Mass Index (BMI), a measurement which compares weight and height and defines people as overweight when their BMl is between $25 \mathrm{~kg} / \mathrm{m}^{2}$ and $30 \mathrm{~kg} / \mathrm{m}^{2}$, and obese when it is greater than $30 \mathrm{~kg} / \mathrm{m}^{2}$.

The physical fitness index (PFI) measures the physical fitness for muscular work and the ability to recover from the work. PFI is one of the important criteria to assess the cardiopulmonary efficiency of a subject [9]. PFI is determined by three recovery pulse rates. It also is a good measurement of fitness and a person's ability to recover after a strenuous exercise.

The aim of the study was to assess and compare the physical activity and cardiorespiratory condition in young normal weight and overweight subjects by comparing Physical Fitness Index (PFI) score and $\mathrm{VO}_{2}$ max.

\section{MATERIALS AND METHODS}

Design of the study was cross sectional and total 80 male students of 1st year MBBS aged between 18 to 24 years participated voluntarily in the study. The study protocol was approved by the Institutional Ethical Committee.

Preparation of subjects: Written informed consent was taken from each subject before entering in study and purpose of the survey was explained to the students.

They had no previous physical training history. They were asked to refrain from eating or drinking at least for an hour and allowed to take rest lying down for half an hour before the actual experiments, so that the heart rate and pulmonary ventilation could settle to a constant value. During experiments the subjects wore light cotton clothes. Before the exercise tests, the age, gender, weight and height of the subjects were measured and BMI was calculated for all subjects.

Evaluation of $\mathbf{V O}_{2}$ max: The step test was performed on a stool of 16.25 inches $(41.3 \mathrm{~cm})$ height for a total duration of 3 minutes at the rate of 24 cycles per minute. After completion of the exercise, the subject was asked to remain standing and the carotid pulse rate was measured from 5-20 seconds of the recovery period. This 15 second pulse rate was converted into beats per minute and the following equations were used to predict the maximum oxygen uptake capacity [10-11]:

In Males, $\mathrm{VO}_{2} \max (\mathrm{ml} / \mathrm{kg} / \mathrm{min})=55.23-(0.09 \mathrm{x}$ pulse rate in beats $/ \mathrm{min}$ )

Physical fitness index: Physical fitness index of each subject was recorded by using modified Harvard step test with step height $41.3 \mathrm{cms}$. Demonstration of the correct stepping procedure was given to each subject. The subjects were asked to step up and down on the platform at a rate of 20 steps per minute for 5 minute or until exhaustion. (Exhaustion is defined as when the client cannot maintain the stepping rate for 15 continuous second). When the subject successfully completed the test, counting of recovery time was started. He was made to sit quietly on a chair or lie on the cot. Three readings were taken during this recovery phase. The first reading was from 1 minute to 1 minute 30 seconds after the exercise, the second reading was from 2 minutes to 2 minutes 30 seconds after the exercise and the third reading from 3 minutes to 3 minutes 30 seconds after the exercise. 
The Physical Fitness Index is calculated by using following formula [12]:

$$
P=\frac{\text { Duration exercise ( in sec.) } \times 100}{2 \text { (PR1 + PR2 + PR3) }}
$$

Statistical Analysis was performed using SPSS version 20.0 statistical package for windows (SPSS, Chicago, IL). Continuous variables were expressed as mean +/-S.D. and qualitative data was expressed in percentages. The association between continuous variables was tested by linear correlation using Pearson's coefficient. All tests were two tailed, confidence intervals were calculated at $95 \%$ level and a p-value of $<0.05$ was considered significant. Scatter-plot summarizes the findings in picture.

\section{RESULTS}

In this study, 80 healthy adult males were taken and their $\mathrm{VO}_{2}$ max was studied and physical fitness index was calculated. The physical characteristics, $\mathrm{VO}_{2}$ max and physical fitness index of the participants are presented in table 1.

The average age of the subjects was $19.53 \pm 1.47$ years, the average height was $162.27 \pm 5.20 \mathrm{~cm}$, and the average BMI was $25.53 \pm 2.59 \mathrm{~kg} / \mathrm{m}^{2}$. The average resting heart rate was $76.83 \pm 5.22 \mathrm{bpm}$, the average $\mathrm{VO}_{2} \mathrm{max}$ was $36.60 \pm 3.64(\mathrm{ml} / \mathrm{kg} /$ $\mathrm{min}$ ) and the average PFI was 98.09 \pm 5.67 .

According to PFI score ratings of each subject in study, they were classified in different grades. The number of students in different PFI grades is shown in Table 2.

Table 1: Physical characteristics, $\mathrm{VO}_{2}$ max and physical fitness index of subjects.

\begin{tabular}{|l|c|}
\hline \multicolumn{1}{|c|}{ Variables } & Values (Mean \pm SD) \\
\hline Age $(\mathrm{yr})$ & $19.53 \pm 1.47$ \\
\hline Height $(\mathrm{cm})$ & $162.27 \pm 5.20$ \\
\hline $\mathrm{BMI}\left(\mathrm{kg} / \mathrm{m}^{2}\right)$ & $25.53 \pm 2.59$ \\
\hline Resting Heart Rate $(\mathrm{bpm})$ & $76.83 \pm 5.22$ \\
\hline $\mathrm{VO}_{2} \mathrm{max}(\mathrm{ml} / \mathrm{kg} / \mathrm{min})$ & $36.60 \pm 3.64$ \\
\hline PFI & $98.09 \pm 5.67$ \\
\hline
\end{tabular}

Table 2: Distribution of PFI score.

\begin{tabular}{|c|c|}
\hline PFI ratings [13] & $\begin{array}{c}\text { Number of } \\
\text { students }\end{array}$ \\
\hline Excellent(>115) & 2 \\
\hline Good(103-115) & 16 \\
\hline Fair(91-103) & 52 \\
\hline Poor(<91) & 8 \\
\hline
\end{tabular}

Pearson product-moment correlation coefficient was computed to assess the relationship between the $\mathrm{VO}_{2}$ max and $\mathrm{BMI}$ in the subjects. There was a negative significant correlation between the two variables $(r=-0.392, p<0.01)$. The scatter plot in figure 1 summarizes the results.

The scatterplot in Figure 2 shows the relationship between the PFI and BMI in the subjects. There was a negative significant correlation between the two variables $(r=-0.225, p<0.05)$.

Fig. 1: Graph showing relationship between $\mathrm{VO}_{2} \max$ and BMI.

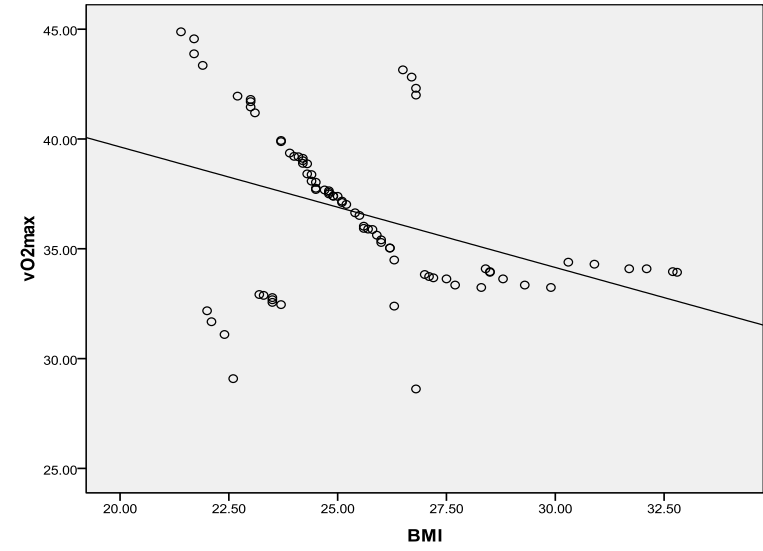

Fig.2: Graph Showing Relationship Between PFI And BMI.

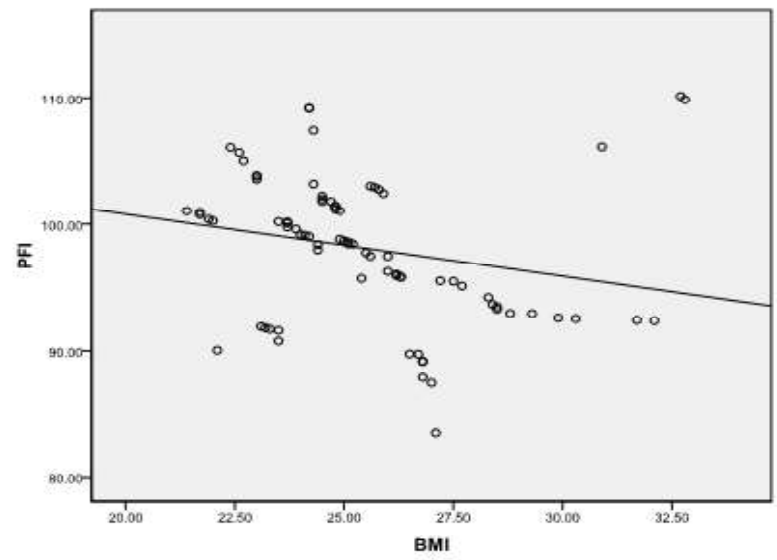

\section{DISCUSSION}

In our study, cardiopulmonary fitness parameters included $\mathrm{PFI}$ and $\mathrm{VO}_{2}$ max. The average $\mathrm{VO}_{2} \max$ was $36.60 \pm 3.64(\mathrm{ml} / \mathrm{kg} / \mathrm{min})$ that is somehow less than the values in other similar studies. Body mass index is an important indicator to evaluate whether an individual is overweight or normal. In our study average subjects are overweight but not in obese category.

The findings of the present study show moderate negative correlation between B.M.I. and $\mathrm{VO}_{2}$ max in all students. The $\mathrm{VO}_{2}$ max level decreased 
significantly in higher BMI. This study shows that a normal BMI is required for good cardio-respiratory fitness which is consistent with the study done by Wei et al [14] and Banerjee et al [15]. Shrivastav et al. (2013) conducted a similar study on 22 young subjects in the age group of 18-25 years which concluded that there was a negative significant correlation ( $r=-0.55)$ between BMI and aerobic fitness [16].

As a person becomes more obese, the body becomes less sensitive, further limiting the scope of everyday activities. Most of the existing studies restricted the key evaluation parameters of fitness level to $\mathrm{VO}_{2}$ max, which is an indicator of cardio-respiratory endurance. This might be the probable cause for having significantly greater $\mathrm{VO}_{2}$ max among males as they in turn showed significantly higher values of physical parameters.

The current study evaluated other fitness parameter $\mathrm{PFI}$, in addition to $\mathrm{VO}_{2} \mathrm{max}$, to analyze the fitness level differences between obese and average subjects. The Harvard test is a submaximal fitness test, as it predicts cardiovascular fitness (endurance) from the rise of heart rate during moderate exercise, rather than exercise to exertion. The subjects were more in fair and good score group of PFI. Chatterjee et al [17] showed higher PFI score in trained (athletics) than those of untrained (non-athletics) but comprising of female subjects only. Das SK et al [18] also studied PFI with modified Harvard test in young men and women. Their study restricted to untrained subjects only.

In our study, the greater mean PFI score reflects a greater cardiovascular fitness. The negative correlation between $\mathrm{BMI}$ and $\mathrm{PFI}$ score shows that, greater the BMI of these children is lesser the physical fitness index. Fitness capacity therefore decreased progressively as the BMI increased. These results correlate with other studies that researched the same variables [1920]. There was a negative significant correlation between health-related anthropometric measures and physical fitness factors as per Leila Jaafari et al [21].

Physical Fitness Index depends on recovery of the heart rate after exercise and therefore is seen to be less in the overweight group as the over- weight group has a higher resting heart rate due to altered sympathetic activity and also the return to resting is prevented by the altered function of the sympathetic nervous system. Gupta et al (1967) stated that PFI is related to recovery pulse rate. The reason for this may be recovery pulse in early phase after severe exercise is a function of hemodynamics and is beyond voluntary control [22]. The recovery period depends on how intense of an exercise you perform, as well as your overall fitness level. Any increase in energy expenditure requires rapid adjustments in blood-flow that affect the entire cardiovascular system. The present study showed that fitness of medical students is not good. This study has clearly established that physical activity is an important determinant and predictor of physical fitness.

The present study is limited to a small bout of exercise and is conducted on healthy student volunteers. This study only clarifies the correlation between BMI and physical fitness; it does not demonstrate a causal relationship between the two. Further studies have to be conducted on subjects with larger sample size; on patients during the hospital stay. For better results the future study should involve more specific parameters and should be done on more than one occasion after physical training.

\section{CONCLUSION}

The physical fitness of subjects varies inversely with the BMI. Increased BMI pose increased risk of additional health problems. The students should be encouraged to take part in various physical activities.

\section{ACKNOWLEDGEMENT}

The authors would like to thank all the students who participated in the study.

\section{REFERENCES}

[1]. Clark HH : President's Council on Physical Fitness and Sports. Physical Fitness Research Digest (Series 1, No. 1). Washington, DC: Author, 1971.

[2]. McArdle WD, Katch FI, Katch VL: Exercise Physiology, Energy, Nutrition and Human Performance. Philadelphia: Lea and Febiger 1986;539-542.

[3]. Roca J, Rabinovich R: Clinical exercise testing. Eur Respir Mon 2005;31:146-165.

[4]. Richardson RS: Oxygen transport and utilization, an integration of muscle systems. Advan Physiol Educ 2003;27:183-191. 
[5]. Fox, EL:A simple accurate technique for predicting maximal aerobic power. Journal of Applied Physiology, 1973;35:914-916.

[6]. McArdle,WD, Katch, FI and Pechar, GS: Reliability and interrelationships between maximal oxygen intake, physical work capacity and step test scores in college women. Medical Science of Sports \& Exercise, 1972;4:182-186.

[7]. Chatterjee S, Chatterjee P, Mukherjee PS, Bandyopadhyay A: Validity of Queen's college step test for use with young Indian men. Br J Sports Med 2004;38:289-291.

[8]. Wei M, Kampert JB, Barlow CE, Nichaman MZ, Gibbons LW, Paffenbarger RS and Blair SN: Relationship between low cardiorespiratory fitness and mortality in normal-weight, overweight, and obese men. JAMA 1999;282(16):1547-1553.

[9]. Sunil KR, Das: Determination of physical fitness Index (PFI) with modified Harvard Step Test (HST) in young men and women. Ind J Physiol \& Allied Sci 1993;47(2):73-76.

[10]. Chatterjee, S., Chatterjee, P. and Bandyopadhyay, A. Validity of Queen's College Step Test for estimation Maximum oxygen uptake in Young Indian Women. Indian Journal of Medical Research, 2005;121:3235.

[11].Chatterjee, S., Chatterjee, P., Mukherjee, P.S. and Bandyopadhyay, A. Validity of Queen's College step test to use with young Indian men. British Journal of Sports Medicine, 2004;38:289-291.

[12]. Brouha L, Health CW, Graybiel A: Step test simple method of measuring physical fitness for hard muscular work in adult men. Canadian Review; 1943;2: 86-92.

[13]. Taylor KL, Buskirk R, Henschel A. Maximum oxygen intake as an objective measure of cardio-respiratory performance. J. Appl. Physiol, 1955; 8:73-80.
[14]. Wei, M., Kampert, J.B., Barlow, C.E., Nichaman, M.Z., Gibbons, L.W., Paffenbarger, R.S. and Blair, S.N. Relationship between low cardiorespiratory fitness and mortality in normal-weight, overweight, and obese men. JAMA 1999;282(16):1547-1553.

[15].Banerjee, P.K., Chatterjee, S., Chatterjee, P. and Maitra, S.R. Aerobic capacity of Bengalee young men trained and untrained. Indian Journal of Physiology \& Allied Sciences, 1974;28:91-99.

[16]. Srivastava, S., Dhar, U. and Malhotra, V. Correlation between Physical Fitness and Body Mass Index. IJCRR, 2013;5:44-48.

[17]. Chatterjee S, Mitra A. The relation of physical fitness score with different morphological parameters and $\mathrm{VO}_{2}$ Max on adult female Athletes and Non athletes. Indian J Physiol Allied Sci 2001;55:7-11.

[18]. Das SK, Mahapatra S. Determination of physical fitness index (PFI) with modified Harvard Step Test (HST) in young men and women. Indian J Physiol Allied Sci 1993;47:73-75.

[19]. Chen, L.J., Fox, K.R., Haase, A., Wang, J.M. Obesity, fitness and health in Taiwanese children and adolescents. Eur. J. Clin. Nutr., 2006;60:1367-75.

[20]. Tokmakidis, S.P., Kasambalis, A., Christodoulos, A.D. Fitness levels of Greek primary schoolchildren in relationship to overweight and obesity. Eur. J.Pediatr., 2006;165:867-874.

[21]. Jaafari, Leila. Health-related anthropometric measures in connection with physical fitness factors; IPEDR International Proceedings of Economics Development and Research, 2012;31:21-24. http:// www.ipedr.com/list-59-1.html

[22]. Gupta KK. The use of the physical efficiency tests in the evaluation of physical improvement after a military course involving severe physical strains. Indian J Physiol and Pharmacol 1967;11(3):89-93.

How to cite this article: Ibrahim Farooque, Gauhar Hussain. THE

RELATIONSHIP BETWEEN PHYSICAL FITNESS PARAMETERS AND BODY MASS INDEX IN YOUNG HEALTHY SEDENTARY ADULTS. Int J Intg Med Sci 2017;4(6):512-516. DOI: 10.16965/ijims.2017.113 